\title{
Poesia na rede: as novas tecnologias no ensino de língua inglesa
}

\author{
Layssa Gabriela Almeida e Silva*
}

\begin{abstract}
Resumo
O presente estudo tem por objetivo analisar a importância que textos poéticos previamente selecionados podem desempenhar no ensino de línguas estrangeiras mediado pelas novas tecnologias. Foi desenvolvido um estudo de caso com alunos do nono ano do ensino fundamental de uma escola pública da cidade de Goiânia, em que se buscou incentivar a análise de poemas através dos e-mails dos participantes. As atividades realizadas pelos alunos são descritas e algumas contribuiçôes são apresentadas aos docentes que buscam trabalhar com poemas em sala de aula. A partir do estudo de caso realizado, conclui-se que a leitura de textos poéticos é um meio eficaz no ensino da língua inglesa, além de ser uma atividade indispensável na formação de um leitor crítico.
\end{abstract}

Palavras-chave: ensino, língua inglesa, e-mail, poesia.

Poetry on the net: the new technologies in English language teaching

\begin{abstract}
The aim of this study is to analyze the importance of previously selected poetic texts in the teaching of foreign language using the new technologies. A case study involving ninth graders at a state elementary school in Goiânia sought to encourage analysis of poems through the e-mails of participants. The activities carried out by the students are described and some contributions are presented for teachers wishing to use poems in the classroom. From this case study, it can be concluded that the reading of poetry is an effective means of teaching English as well as being an essential activity for the formation of critical readers.
\end{abstract}

Keywords: teaching, English language, e-mail, poetry.

O trabalho com a literatura, sobretudo a poesia, em aulas de línguas, tem sido descrito como uma oportunidade de introduzir língua autêntica (tal como foi produzida, ou seja, sem sofrer alterações para fins pedagógicos) em sala de aula, dando aos alunos a oportunidade de desenvolver o gosto pela arte e o contato com um tipo de produção linguística não alterada didaticamente (ABREU E NASCIMENTO, 1998; SABOTA E VIEIRA, 2003).

\footnotetext{
* Bolsista do CNPq, mestranda em Estudos Linguísticos pela Universidade Federal de Goiás. E-mail: layssagabriela@hotmail.com
} 
Em sua primeira experiência como professora na educação básica, esta pesquisadora teve a oportunidade de trabalhar com seus alunos do ensino fundamental de Língua Inglesa a leitura de alguns poemas em inglês do escritor americano Shel Silverstein. Após a leitura e a interpretação em grupo dos poemas, os alunos, individualmente, iniciavam o processo de criaçáo dos seus próprios poemas. Em um segundo momento, nessa mesma escola, ela participou de um projeto de concurso de poesia, no qual os alunos deveriam criar um poema em língua estrangeira sobre sua escola. Foi feita uma seleção desses poemas na escola entre os professores de línguas e os melhores poemas foram publicados em uma revista, o que motivou e encheu de orgulho alunos, pais e responsáveis.

Havia sido, pois, despertado o interesse por continuar trabalhando com o gênero poético nas aulas de Língua Inglesa. Entretanto, uma curiosidade maior lhe ocorreu: o que poderia acontecer se os alunos, nativos digitais que são, pudessem unir algo que lhes é tấo caro, presente e atual (tecnologia) com algo que vinha sendo trabalhado como conteúdo complementar em aulas de línguas estrangeiras (poesia)? Surgia, então, a proposta deste estudo interligando o uso das Novas Tecnologias de Informação e Comunicação (NTICs) nas aulas de línguas estrangeiras associado ao ensino de poesia em língua inglesa.

As TICs ou NTICs podem ser definidas como tecnologias usadas para reunir e compartilhar informaçóes embasadas no uso da oralidade e da escrita em sua "síntese entre som, imagem e movimento" (KENSKI, 2011, p. 28). Também chamadas pela autora de "tecnologias de inteligência", possuem uma base imaterial que se concretiza na linguagem e, no âmbito educacional, tendem a ser vistas como potencializadoras dos processos de ensino.

Corrêa (2006, p. 47), no entanto, apresenta uma ressalva em relação às TICs. Segundo a autora, "as tecnologias que favorecem o acesso à informação e aos canais de comunicaçáo não são, por si mesmas, educativas, pois, para isso, dependem de uma proposta educativa que as utilize como mediação para uma determinada prática educativa. Assim, no âmbito educacional, seria necessário primeiramente que o docente fizesse um levantamento para averiguar quais tecnologias possui ao seu dispor e verificar quais delas poderiam ser utilizadas para desenvolver um trabalho pedagógico.

Sabe-se que muitas das novas tecnologias vieram para facilitar ainda mais o dia a dia da população mundial. No entanto, quando se fala sobre 
o uso dessas novas tecnologias no campo educacional, há, segundo Corrêa (2006), duas visóes distintas por parte dos educadores, a tecnofóbica e a tecnofílica. Os adeptos da primeira visão acreditam que a máquina é capaz de substituir o homem e de promover a perda das relaçóes afetivas; por isso apresentam uma grande resistência ao uso das novas tecnologias. Os últimos acreditam que a máquina é capaz de resolver todos os problemas educacionais e por isso passam a divinizá-las.

Sem extremismos, é preciso perceber que a máquina por si só não é panaceia, ou seja, a solução para todos os problemas Ademais, como afirma Gadotti (1994), cabe reconhecer que nenhuma tecnologia é tão perfeita que possa dispensar aquele que organizou a atividade didática. Cabe ao professor, pois, compreender primeiramente a realidade em que vive para perceber seu real papel de formador de indivíduos capazes de usar essas novas tecnologias que os cercam.

Carvalho (2000) concorda com essa afirmação ao enfatizar que tanto a capacidade dos humanos quanto a capacidade dos computadores poderiam ser potencializadas na medida em que atuassem em parceria, pois, apesar de os computadores serem muito rápidos, eles só atuam de forma pré-programada, enquanto os humanos têm uma enorme capacidade de programar algo a partir de informaçóes recebidas.

Negroponte (apud CARVALHO, 2000) afirma ainda que uma das maneiras de se convencer alguém com tecnofobia a se sentar em frente ao computador é

ter em mente que a tecnofobia não é injustificável: os micros estâo cada vez mais complexos e o uso deles tem se tornado uma situação cada vez mais humilhante. Na maioria dos casos, o pior caminho para esclarecimento é levar uma pessoa para uma escola. [...] O tecnofóbico precisa sentir, antes de tudo, que a nova habilidade é uma questão de vida, não de computadores. (NEGROPONTE apud CARVALHO, 2000, p. 155)

Assim, é necessário buscar meios distintos a fim de que o tecnofóbico possa perceber a necessidade de conhecer/compreender as novas tecnologias, para se inserir nessa sociedade onde cada vez mais indivíduos estão se relacionando virtualmente. Cabe ressaltar que, atualmente, tal adjetivo não se restringe meramente aos alunos, mas principalmente aos docentes, que em muitas situaçóes se sentem inseguros frente ao uso das novas tecnologias. 
Diante da afirmação de que as novas tecnologias estáo sendo cada vez mais usadas por todos os indivíduos, surge um questionamento: se os indivíduos já estão fazendo uso dessas novas tecnologias, por que não inserilas na realidade da sala de aula?

A inserção das novas tecnologias na sala de aula se torna relevante, pois, segundo liçáo de Sampaio e Leite (2004), tanto professores quanto alunos devem saber usar as novas tecnologias e refletir sobre seu uso para atuarem na sociedade como indivíduos que as dominam e que não são dominados por elas. E para que professores e alunos saibam refletir e usar criticamente as novas tecnologias se torna imprescindível que eles possam compreender melhor como se dá o processo de aprendizagem na era digital.

\section{A aprendizagem na era digital: aspectos motivacionais e implicaçóes para o ensino}

Lévy (1999) afirma que quase metade da sociedade está ou gostaria de estar na escola. Esse fato contribuiu para mudar a realidade da educação até então vigente, pois, com a dificuldade em "aumentar a demanda de professores proporcionalmente à demanda por formação" (LÉVY, 1999, p. 169), houve uma busca por meios alternativos para suprir essa carência, daí o surgimento dos cursos de ensino a distância (EAD).

A educação a distância é, para Moran (2002), um tipo de educação em que professores e alunos estão separados espacial e/ou temporalmente. Desse modo, um curso a distância pode ser realizado de formas distintas - através de correspondência, televisão, vídeos, ou, ainda, através da internet.

Outra forma de aprendizado que tem sido bastante difundida recentemente é a chamada blended learning (SHARMA, 2010), a qual busca aliar/ combinar o uso de materiais impressos e digitais em cursos semipresenciais. Segundo Oliver e Trigwell (2005 apud SHARMA, 2010), o blended learning poderia ser visto ainda como uma combinação entre a aprendizagem tradicional e a aprendizagem tecnológica.

Um simples exemplo desse tipo de aprendizagem pode ser evidenciado quando o professor, após ter discutido um poema em sala com os alunos, lhes envia através do e-mail endereços eletrônicos que proporcionam o acesso a vídeos, ou ainda, a sítios que complementam o que foi visto em sala de aula. Por permitir que o aprendizado ocorra de forma mais flexível, o blended learning será utilizado nesse estudo. 
Diante dessa realidade de novas tecnologias, o professor acaba se questionando sobre o que deve/pode ser feito para motivar seus alunos não somente a aderir a essas modalidades, mas principalmente a participar das atividades propostas, visando construir um conhecimento. Assim, tem-se como necessário um delineamento mais preciso a respeito do tema "motivação".

Buscando definir o termo em um contexto mais específico, o da sala de aula, Gardner e Lambert (1959 apud LARSEN-FREEMAN e LONG, 1991) citam a existência de dois tipos de motivação: a integrativa e a instrumental. A primeira estaria relacionada àquele que busca aprender uma determinada língua, pois se identifica com determinado grupo etnolinguístico, e a última, ao aprendiz que se sente motivado por alguma razão funcional, tal como, passar em uma prova ou conseguir um emprego melhor.

Ellis (1997) complementa a definição de Gardner e Lambert apontando a existência de mais dois tipos de motivação: a resultante e a intrínseca. A motivação resultante é aquela que ocorre no nível extrínseco, ela se torna a causa e o resultado do aprendizado de uma língua. Já a intrínseca é aquela na qual a vontade/desejo de aprender determinada língua vem de dentro do aprendiz, e ele nem sabe dar explicaçôes sobre essa causa.

Existem outros teóricos (Brophy, 1983; Ames e Ames, 1984; Ames, 1990 apud Bzuneck, 2001) que postulam que a motivação deve ser vista sob dois aspectos distintos: o quantitativo e o qualitativo. Em termos quantitativos, "a motivação pode ser maior ou menor, isto é, mais ou menos intensa” (BZUNECK, 2001, p. 15), sendo, no entanto, necessário que os docentes desmistifiquem a crença de uma linearidade entre motivação e desempenho. Nem sempre quem é muito motivado apresenta um bom desempenho; ademais, "níveis excessivamente elevados de motivação rapidamente acarretam fadiga e o mais grave é que aí surge a emoção negativa da alta ansiedade" (Naveh-Benjamin, Mckeachie e Lin, 1987 apud Bzuneck, 2001, p. 18), que tende a prejudicar o aprendizado. Sendo assim, a motivação ideal em contextos educacionais "deve ser branda e vigilante, caracterizada mais pela qualidade do que pela intensidade" (BZUNECK, 2001, p. 18).

Ao analisar a motivação quanto aos aspectos qualitativos é possível afirmar que "existem tipos de motivação menos adaptadores e menos eficazes do que outros" (BZUNECK, 2001, p. 18), uma vez que há alunos motivados, mas que - por razóes errôneas, tais como querer fazer rápido 
as atividades para entregar logo, ou ainda devido à preocupaçáo excessiva com notas ou reprovação escolar - acabam demonstrando um envolvimento menor com a aprendizagem e, consequentemente, apresentam resultados inferiores.

Ao analisar os diversos tipos e as peculiaridades da motivação, notase o quão difícil pode ser para o professor motivar seu aluno, pois, como já citado anteriormente, ela não depende exclusivamente do empenho do professor, mas, em grande parte, das características individuais dos alunos. As características individuais se tornam ainda mais aguçadas no período da adolescência, época em que o ser humano está se descobrindo e passando por inúmeras mudanças biológicas, sociais e afetivas. Todas essas mudanças propiciam um comportamento diferenciado por parte dos adolescentes que, em alguns momentos apresentam "estados de fragilidade e agressividade, de total desprezo e descaso, [e em outros] total paixão e envolvimento em busca de um ideal" (BASSO, 2008, p. 127).

Bzuneck (2001, p. 26) diz que "de um ponto de vista psicoeducacional, o papel do professor em classe, mais do que remediar (o que, porém, não deve ser descuidado), é o de prevenir a ocorrência de condiçóes negativas", com o intuito de manter a motivaçáo positiva nas séries ao longo dos anos.

Para atingir esse aluno adolescente o professor deve, pois, buscar respaldo em todas as teorias que a ele foram apresentadas durante a sua formação universitária para analisar quais delas devem ser aplicadas a cada grupo escolar. Além da assistência proporcionada pela teoria, muitos professores têm encontrado auxílio na utilização das novas tecnologias, que têm proporcionado novas formas de aprendizado.

Feita a explanação a respeito da importância da tecnologia na sala de aula cabe agora expor como a literatura, mais especificamente a poesia, tem sido trabalhada na sala de aula de língua inglesa.

\section{Literatura em Língua Estrangeira: o gênero poético nas aulas de Língua Inglesa}

Ao fazer um levantamento histórico sobre o ensino de literatura e o ensino de Língua Inglesa, Abreu e Nascimento (1998) evidenciam que o ensino de língua inglesa esteve associado ao ensino de literatura no Brasil até o início dos anos 1960. Segundo as autoras, além de os alunos decorarem poemas e citaçóes literárias, os professores faziam uso de gramáticas e antologias poéticas para ensinar língua estrangeira. 
Após os anos 1960 "os professores deram uma ênfase à língua escrita e a literatura foi posta de lado como forma arcaica e cristalizada de linguagem. A partir daí, os textos literários passaram a ser considerados muito conservadores e complicados" (ZYNGIER apud ABREU e NASCIMENTO, 1998, p. 34).

Essa visão de que os textos literários abrangem apenas as formas arcaicas e cristalizadas da linguagem é combatida por Barstürkmen (1990 apud ANSPACH, 1998, p. 7), para quem a "literatura contribui para o propósito de aprendizado de língua e ela representa a linguagem em uso". Nesse sentido, o incentivo à leitura de textos literários tem ganhado um espaço considerável nas aulas de língua estrangeira.

Contudo, como, em geral, o tempo das aulas é reduzido, "só há espaço para leitura de textos curtos e simples, os quais tendem a ser explorados com perguntas previamente preparadas que não contemplam a especificidade da leitura individual de cada aluno" (PAULINO e COSSON, 2009, p. 73). Quando se sabe que a transposição dessa simples decodificação de palavras na busca do sentido real do texto poético é, segundo Cunha (1976) e Culler (2001), um dos primeiros passos para que o leitor se torne crítico e proficiente.

Passa-se agora à explanação metodológica desse estudo.

\section{As características da pesquisa}

Esta é uma proposta de estudo qualitativa, cujas quatro características principais, segundo Creswell (2007, p. 186), são: a ocorrência em um cenário natural; o fato de ser fundamentalmente interpretativista; a busca dos pesquisadores em considerar a opiniâo dos participantes durante a pesquisa; e a existência de uma maleabilidade quanto às questóes de pesquisa, que podem sofrer alteraçóes de acordo com o andamento do estudo. Dentro do escopo qualitativo, esta pesquisa se caracteriza como um estudo de caso.

Este estudo foi realizado na última série do ensino fundamental de uma escola pública da cidade de Goiânia, durante os meses de abril e junho de 2011. Essa escola apresenta um bom aparato tecnológico. A sala de aula de língua estrangeira possui uma televisão e aparelhos de som e DVD, bem como um data show que fica disponível para o uso dos professores de línguas. A escola também possui um laboratório de línguas com vinte computadores com acesso à internet. 
$\mathrm{Na}$ escola há uma divisão das turmas nas aulas de línguas estrangeiras com o intuito de viabilizar a interação entre professor e alunos. Cada série possui duas turmas de trinta alunos, $\mathrm{A}$ e $\mathrm{B}$, que são redivididas para a criação de uma turma C. Assim, cada turma de línguas fica com um total de vinte alunos. Por isso, pode-se dizer que esta pesquisa abrangeu um terço dos alunos do $9^{\circ}$ ano da escola referida.

Dos vinte alunos da turma, apenas dezoito se disponibilizaram a participar da pesquisa. Um dos alunos justificou a sua náo participaçáo por falta de autorização do pai, enquanto a outra afirmou que não participaria por falta de tempo para se dedicar à realização das atividades. Vale destacar que a pesquisadora era também professora da turma e que não foram atribuídas notas/conceitos a nenhuma atividade realizada durante a pesquisa.

A turma foi escolhida para a pesquisa, pois, por se tratar de uma turma do último ano do ensino fundamental, acredita-se que eles já apresentem um bom domínio gramatical e, consequentemente, pela idade, maturidade para realizar atividades a distância.

Feita a escolha da turma, o próximo passo foi a escolha dos poemas que condissessem com o nível dos alunos. Para isso houve um enorme cuidado quanto ao tamanho e tema dos poemas. Os dois poetas escolhidos, Margaret Walker e Gil Scott-Heron, são poetas afro-americanos. Gil ScottHeron ficou conhecido por suas poesias cantadas misturadas a ritmos distintos. O poema musicado "The revolution will not be televised", foi escolhido para ser trabalhado com os alunos, pois, apesar de ser um pouco extenso, sua estrutura é bem simples, há muitas repetiçôes dos versos, e além do mais há vídeos que o ilustram.

Após a escolha da turma e dos materiais, realizou-se o processo de coleta de dados a fim de averiguar como os alunos reagiriam à inserção das novas tecnologias na sala de aula e qual seria a recepção deles quanto à leitura de poesia em língua inglesa.

Inicialmente havia uma pretensão de que este estudo fosse desenvolvido totalmente a distância. Contudo, como alguns alunos precisaram de apoio quanto ao acesso à internet, foram disponibilizadas seis aulas para que eles desenvolvessem as atividades. Estando a professora pesquisadora presente com os alunos nessas aulas, o estudo deixou de ser exclusivamente a distância, tornando-se semipresencial. E sendo semipresencial, com a utilização de materiais impressos e digitais, caracteriza-se, como já adiantado acima, como blended learning. 


\section{Instrumentos de coleta de dados}

Foram entregues aos alunos dois questionários abertos, um inicial e outro final. O questionário inicial teve como objetivos: permitir que os alunos escolhessem pseudônimos a serem usados no estudo para que sua identidade fosse preservada; reconhecer o perfil dos alunos e seus conhecimentos de textos literários em língua inglesa. O questionário final buscou colher as percepçóes dos alunos acerca da pesquisa, a fim de apontar os pontos positivos e negativos do uso das tecnologias nas aulas de língua inglesa.

Também integram o corpus deste estudo os registros das interaçóes virtuais (e-mail, lista de discussóes, vídeos) e um diário digital da pesquisadora, com o propósito de retratar as percepçóes sobre, durante e após a pesquisa.

Assim, a partir dos questionários, do registro das interaçóes virtuais e do diário da professora pesquisadora, foi possível fazer uma triangulação dos dados.

Cabe ressaltar que se encontram no registro das interaçóes virtuais cinco atividades distintas que foram solicitadas aos alunos durante a pesquisa. Na primeira delas, os alunos deveriam ler um texto que continha dicas para a apreciação do gênero poético. Após a leitura do texto, os alunos deveriam clicar em um link que os conduzia a uma enquete.

A segunda atividade buscava analisar qual a percepção inicial que os alunos apresentavam sobre poesia. Para isso, foi enviado ao $e$-mail deles a pergunta: "What is poetry for you?". Os alunos tinham a liberdade para respondê-la em inglês, ou, ainda, utilizar sua língua materna. $\mathrm{Na}$ terceira atividade foi enviado um handout aos alunos, que após ser feito e salvo no computador por eles, deveria ser enviado ao e-mail da professora pesquisadora.

A quarta atividade era embasada em um vídeo. Após clicarem em um link (http://www.youtube.com/watch?v=BS3QOtbW4m0) que os conduzia a um site de compartilhamento de vídeos, os alunos deveriam responder no corpo do e-mail a algumas questóes de interpretação sobre o vídeo. E, por fim, a quinta atividade consistia no acesso a um site (http://translate.googleusercontent.com/translate_c?hl=pt-BR\&langpair=en|pt\&u=http://www. readwritethink.org/files/resources/interactives/acrostic/\&rurl=translate. google.com.br\&usg=ALkJrhgF0H6ssnt8M7su5PA-ObQiD7Fc-Q), que 
auxiliava os alunos na criação de acrósticos, composição poética cujas letras iniciais de cada verso formam palavras. Cada aluno, após a criação do seu acróstico, deveria imprimir e entregar seu poema à professora pesquisadora.

\section{Discussáo dos dados}

Durante a análise dos dados, foram observadas as respostas provenientes das perguntas da pesquisa. Com relação à primeira pergunta, que consistia em averiguar a percepçáo dos alunos a respeito de poesia, foi possível perceber que, para os três alunos que realizaram essa atividade, poesia é um gênero que tem como característica a expressão de sentimentos. Tal fato pode ser evidenciado em:

Poetry is when we open our hearts to show our feelings in words.

(Érica, atividade 2)

Poetry is an expression of feelings in verse form.

(Emily, atividade 2)

Poetry to me is culture.

(May, atividade 2)

As respostas do primeiro questionamento foram posteriormente analisadas no questionário final, onde os alunos tiveram a oportunidade de refletir sobre sua participação na pesquisa e verificar se sua percepção inicial havia sofrido alterações no que diz respeito à poesia. Emily, por exemplo, evidenciou, no questionário final, que a participaçáo na pesquisa a expôs a diversos tipos de poemas que fizeram com que ela gostasse mais de poesia.

$\mathrm{Na}$ quarta atividade, por exemplo, em que os alunos deveriam assistir a um vídeo em um site de compartilhamento de vídeos e, em seguida, responder se tal vídeo tinha características de um poema, oito, dos onze alunos que realizaram essa atividade conseguiram perceber a relação do vídeo com um poema. Através da resposta foi possível averiguar mais claramente a noçẫo que eles tinham de poesia. Quatro alunos, por exemplo, estavam mais atentos aos aspectos formais do texto e do vídeo: 
Eu acho que tem características de um poema; as características são a rima e a repetição de palavras.

(Lola, atividade 4)

Sim, o fato de voltar ao tema toda vez que a TV cai.

(Finotti, atividade 4)

Sim, porque parece que as frases estão sendo rimadas.

(Jordana, atividade 4)

Sim, pois o vídeo é formado por lance de imagens, como verso de poemas.

(Emily, atividade 4)

Enquanto outros três pontuaram aspectos relacionados ao conteúdo:

Eu acho que sim, pois ele fala da vida das pessoas.

(Juice Fruit, atividade 4)

Sim, poemas não têm coisas só boas, e sim ruins, podem ser $\mathrm{da}$ imaginação ou da realidade.

(Priscilla, atividade 4)

Bom, pode ser que sim, já que mostra fatos que chocam e que podem interessar o público, o leitor.

(Cecília, atividade 4)

As respostas dadas a essa atividade sobre o vídeo demonstram que os alunos apresentam conhecimento estrutural (forma, rima, repetição) e de conteúdo sobre poemas. Tal conhecimento apresentado pelos alunos nos permite inferir que a baixa participação dos alunos na segunda atividade, citada anteriormente, em que eles deveriam definir o termo poesia, não se deu pelo desconhecimento desse gênero literário, mas, sim, pela dificuldade supostamente apresentada por eles em definir um termo que, ao menos em princípio, parecia ser algo abrangente.

Analisando a participação dos alunos foi possível inferir que a motivação deles, em termos quantitativos (BZUNECK, 2001), foi maior nas atividades 1,4 e 5 , o que permite deduzir que os alunos se sentiram mais motivados em realizar atividades em que houvesse realmente a necessidade do uso das novas tecnologias para a realização das atividades, e não apenas uma mera transposiçâo da aula tradicional para a tela (LÉVY, 1999). 
Nove alunos pontuaram no questionário final que a atividade 5 foi a que eles mais gostaram de fazer:

A que mais gostei foi o Acrostic poem, pois eu achei interessante encontrar palavras que combina (sic) com a principal.

(Lola, questionário final)

Bem legal porque foi um jeito de se expressar.

(Finotti, questionário final)

A realização dessa atividade foi para muitos dos alunos que participaram da pesquisa, a primeira oportunidade de criar um poema em Língua Inglesa. E acredita-se que tal atividade foi elogiada por muitos dos alunos, porque o site ao qual eles deveriam se dirigir para realizá-la demonstrava de forma simples e dinâmica como fazer um acróstico. Ademais, o próprio site formatava os acrósticos lá realizados com os nomes dos seus respectivos autores, o que dava a impressão de algo realmente feito por um profissional/ artista.

A alta participação dos alunos nessa atividade foi capaz de desenvolver neles o trato com a escrita (PAULINO e COSSON, 2009), pois mesmo os alunos que afirmaram no questionário inicial que tinham dificuldade com a Língua Inglesa e que por isso não gostavam de poesia em inglês, tiveram a oportunidade de manter um contato mais estreito com a língua ao produzir seus próprios poemas e, consequentemente, melhorar sua produtividade escrita.

Outros três alunos apontaram a atividade 4 , a atividade sobre o vídeo The revolution will not be televised, como sendo a de que eles mais gostaram. Alícya, por exemplo, disse:

The revolution will not be televised, because I think that is the reality.

(Alícya, questionário final)

A opinião acerca dessa atividade apresentou divergências: apesar de três alunos a terem apontado como sendo a atividade de que eles mais gostaram, outros oito alunos a apresentaram como sendo a atividade de que menos gostaram.

O vídeo porque não tinha legenda e eu entendi pouca coisa.

(May, questionário final) 
A atividade do vídeo, eu não entendi muito bem o vídeo.

(Pascoal, questionário final)

A fala da May justifica o porquê do alto índice de reprovação por parte dos alunos perante essa atividade. Apesar de o vídeo trazer diversas imagens que o ilustrassem, os alunos não conseguiram compreendê-lo e sentiram falta de uma legenda. Por isso, para uma futura atividade, aconselha-se apresentar aos alunos um vídeo que contenha legenda para facilitar a compreensão.

A última pergunta de pesquisa se refere aos problemas enfrentados por alunos e professores na implementação de exercícios que envolvem poesia em Língua Inglesa associados às novas tecnologias. Foi possível perceber que tais dificuldades se encontravam mais no nível técnico e não efetivamente no desfazer dos alunos em realizar as atividades. $\mathrm{Na}$ atividade do vídeo, por exemplo, os alunos sentiram falta de uma legenda em português para uma melhor compreensão.

Outros quatro alunos afirmaram que tiveram dificuldade para enviar as atividades propostas:

Muito, queria enviar e não enviava, não dava para ir na Lan House... pensei até em desistir, mas não desisti porque gosto muito da professora.

(Priscilla, questionário final)

Sim, o computador não queria abrir as atividades.

(Lola, questionário final)

Sim, em enviar as tarefas, não dava certo às vezes.

(Jordana, questionário final)

$\mathrm{Na}$ verdade eu tive problemas porque eu estava sem computador.

(Cecília, questionário final)

Pode-se notar, na afirmação dada por Priscilla no excerto acima, que os problemas que surgiram no decorrer da pesquisa quase a levaram à desistência; no entanto, o gosto pela professora pesquisadora - presente no nível extrínseco, motivação resultante (ELLIS, 1997) - foi o que a motivou a continuar participando.

Outro ponto que merece destaque foi que, apesar de a grande maioria dos alunos terem evidenciado no questionário inicial que possuíam 
conhecimento e utilizavam a internet com frequência, foi notado que tais usos ainda se restringiam a jogos, sites de relacionamento e mensagens instantâneas. Por isso, houve momentos em que a própria pesquisadora teve que direcionar os alunos quanto ao uso do e-mail, como enviar e anexar arquivos, por exemplo.

Tais direcionamentos fazem parte do papel do professor que busca fazer uso das TICs em suas aulas. Esse profissional deve estar preparado tanto para monitorar as atividades no computador quanto para prever e lidar com algumas dificuldades que porventura possam vir a surgir. Bzuneck (2001, p. 26) afirma ainda que "o papel do professor em sala deve ser não somente o de remediar, mas principalmente o de evitar a ocorrência de condiçôes negativas".

\section{Consideraçóes finais}

Este estudo buscou analisar a percepção que os alunos apresentavam sobre poesia. Buscou também averiguar se haveria engajamento por parte dos alunos em atividades que envolviam poesia em Língua Inglesa. E, por último, foram apresentados os problemas enfrentados por alunos e professores na implementação de exercícios poéticos em Língua Inglesa associados às novas tecnologias.

O contato que os alunos tiveram com diversos tipos de poesia foi capaz de desmistificar a crença que eles tinham de que poesia era um gênero exclusivamente sentimental. Durante a realização da quarta atividade, por exemplo, os alunos afirmaram que poesia poderia abranger diversos temas e pontuaram a existência de outros tipos de poesia, tais como a de protesto.

Com relação às novas tecnologias, foi possível notar que elas podem ser uma grande aliada dos docentes em seu processo de ensino-aprendizagem. Pode-se dizer que a atividade 5, por exemplo, que os alunos apontaram como a que mais gostaram de fazer, foi diferenciada, pois os alunos puderam criar seu próprio poema, não utilizando apenas caneta e papel, mas um site específico que os direcionava na realização da atividade. Tal interesse por parte dos alunos tende a ocorrer, segundo Lévy (1999), quando o professor se propóe a fazer um uso efetivamente genuíno das novas tecnologias, de modo a torná-las insubstituíveis.

A proposta de unir tradição e inovação, apresentado textos poéticos por meio das novas tecnologias, foi muito satisfatória. A leitura e a produção 
de textos poéticos apresentam, como se nota nos resultados desse estudo, grandes vantagens no processo de ensino-aprendizagem, tanto pela melhora da produçáo escrita dos alunos, quanto pela percepção e discussão de questóes sociais presentes nos textos.

Já o contato com as novas tecnologias foi capaz de motivar os alunos a realizarem as atividades propostas e a adquirirem um letramento digital, o que permitiu-lhes ter acesso ao conhecimento nas suas mais diversas formas.

\section{Referências}

ABREU, L.; NASCIMENTO, M. Poemas e ensino de língua inglesa. Claritas, São Paulo, n. 4, p. 33-42, maio, 1998.

ANSPACH, S. Ensino de literatura é o mesmo que ensino de língua? Claritas, São Paulo, n. 4, p. 7-15, maio, 1998.

BZUNECK, J. A motivação do aluno: aspectos introdutórios. In: BORUCHOVITCH, E.; BZUNECK, J. A motivação do aluno: contribuiçóes da psicologia contemporânea. Petrópolis, RJ: Vozes, 2001.

CARVALHO, P. Interação entre humanos e computadores: uma introdução. São Paulo: EDUC, 2000.

CORREAA, J. Novas tecnologias da informação; novas estratégias de ensino/ aprendizagem. In: COSCARELLI, C. Novas tecnologias, novos textos, novas formas de pensar. Belo Horizonte: Autêntica, 2006.

CRESWELL, J. Procedimentos Qualitativos. In: CRESWELL, J. Projeto de pesquisa: métodos qualitativo, quantitativo e misto. 21. ed. Porto Alegre: Artmed/Bookman, 2007. p. 184-210.

CULLER, J. Teoria literária: uma introdução. São Paulo: Beca, 2001.

CUNHA, H. Os gêneros literários. In: PORTELA, E. Teoria literária. Rio de Janeiro: Tempo Brasileiro, 1976. p. 93-131.

ELLIS, R. Second Language Aquisition. New York: Oxford University Press, 1997.

GADOTTI, M. A escola e a pluralidade de meios. Escola e vídeo. Rio de Janeiro, n. 6, p. 32-33, jan. 1994. 
KENSKI, V. M. Educação e tecnologias: o novo ritmo da informação. Campinas: Papirus, 2011.

LARSEN-FREEMAN, D.; LONG, M. An introduction to second language acquisition research. Longman, 1991.

LÉVY, P. Cibercultura. São Paulo: Editora 34, 1999.

MORAN, J. O que é educação à distância. 2002. Disponível em: <http:// www.eca.usp.br/prof/moran/dist.htm>. Acesso em: 21 jun. 2011.

PAULINO, G.; COSSON, R. Letramento literário: para viver a literatura dentro e fora da escola. In: ZILBERMAN, R.; RÖSING, T. (Org.). Escola e leitura: velha crise novas alternativas. São Paulo: Global, 2009.

SABOTA, B.; VIEIRA, T. R. Literature in the language classroom. In: FIGUEIREDO, F. J. Q. de (Org.). Anais do V Seminário de Linguas Estrangeiras. Goiânia: Gráfica e Editora Vieira, 2003.

SAMPAIO, M.; LEITE, L. Alfabetização tecnológica do professor. Petrópolis: Vozes, 2004.

SHARMA, P. Blended Learning. Oxford University Press, 2010.

Recebido em: 30 maio 2012

Aceito em: 15 ago. 2012 